\title{
Ergonomic evaluation of a situation of co- exposure to solvents and noise in a printing of flexible packaging
}

\author{
Mhamdi, A., Ben Amor, A., Amri, A., Youssef, I., Ladhari, N., Gharbi, R. \\ Laboratoire de Toxicologie, d'Ergonomie et d'Environnement Professionnel - Faculté de Médecine de Tunis- \\ Université Tunis ElManar \\ 15, Rue Djebel Lakhdar La Rabta - 1007 Tunis - Tunisie- \\ Tel: (+216)98384134 - email: abada.mhamdi@fmt.rnu.tn
}

\begin{abstract}
The purpose of this paper is to present an ergonomic evaluation of a situation of co-exposure to solvents and noise in a flexible packaging printer. We discuss how such an approach carried out in the field of printing industry work has made it possible to highlight serious shortcomings in the effectiveness of the prevention actions that are supposed to protect workers from chemicals risks and noise. The ergonomic analysis identified a strain working conditions. Indeed, some jobs expose to noise and toxic risk. Lamination operations, winding and cutting are purveyors of noise. Some physical and spatial factors contribute to amplify the toxic risk. The not wearing of personal protective equipment (PPE) by the operators maybe explained by the fact that it doesn't any possibility to do "otherwise". Indeed, operators adopt a compromise to achieve the objectives of production to the detriment of their health and safety. These constraints are causing gene and psychosocial factors. The interviews revealed a state of psychosis in the workshop, which was accentuated by the reclassification of an operator which has created a climate of panic and anxiety especially for older operators who have more than 20 years exposed to handling of toxic and more exposure to high noise level.
\end{abstract}

Keywords: ergonomic analysis "ergotoxicology"; "co-exposure"; "noise"; "solvent"

\section{Introduction}

The sector of packaging and printing occupies an important place in the Tunisian industry. It counts more than 350 companies which employ approximately 17.000 persons.

Occupational exposures in this sector are dominated by several risk factors like: musculoskeletal disorders, high noise levels, chemical risks, which are mainly due to manipulation tasks of various products (inks, solvents, and glues).

The chemicals used are many and varied. There are currently on the market more than 100,000 pure substances which, in combination, give millions of preparations for professional and domestic usage.

Currently, information on the toxicity of these products is still insufficient. Indeed, there is information on 4500 validated products. Chemicals' characteristics, process conditions, and working activities can increase the workplace exposure [Hassim \& Hurme, 2010].

Chemical risks in this sector are mainly due to solvents' absorption, which enter the body primarily through inhalation due to the volatile nature of these substances and through the skin. This absorption of solvents is favored by the lack of information, lack of collective protection and refusal of wearing personal protective equipment (PPE) [Garrigou, et al., 2011; Garrigou, et al., 2009).

The dangers inherent in these products are very varied. This may be of clinical acute or chronic effects, relatively common and severe (asthma, cancer, mental illness) as they may cause undesirable consequences on the environment and safety of employees (explosion, release toxic gases) as the tragedies of SEVESO (Italy in 1976, release 
of dioxins) and Bhopal (India in 1984 release of methyl isocyanate).

This study was initiated by the occupational physician of the company who has identified work situations which involved potential risks to safety and health of employees. His observation was supported by an on sight presence of an occupational disease case (psychosomatic syndrome due to glue-sniffing), recognized by the national insurance (Caisse Nationale d'Assurance Maladie CNAM). The patient received a vocational rehabilitation. Then, there were successive complaints of employees related to poor conditions of work.

This study aimed at evaluating and assessing the risks of co-exposure to solvents and different noise levels in this enterprise (SIED).

\section{Methodology}

The present study used the following data collection tools: (i) ergonomic analysis of work tasks and activities, (ii) observations of working situations, (iii) toxicological data and (iv) noise measurements were taken by a sound level meter (class1), Bruel \& Kjaer, type 2238,. Contamination levels were measured in different stages of the work such as: preparing, printing, lamination, cutting and cleaning. Air samples from the workplace were taken using individual pumps. While concentrations of the chemicals handled were determined by gas chromatography. The environmental monitoring was done in November.

Some operators (10) were interviewed - in situ using a detailed questionnaire, which included inquiries on present employment exposure to solvents and noise.

\section{Results}

\subsection{Presentation of the company:}

This study was carried out in a company of impression on packing for various foodstuffs, created in 1980. It's specialized in the impression on flexible packing, in a large workshop of $2000 \mathrm{~m}^{2}$ a surface and $8 \mathrm{~m}$ of roof height, divided into several units:

- Print unit "Soloflex"

- Print unit "Helio"
- Unit of lamination

- Storeroom of raw materials and finished products

- Additional units, located outside the principal workshop, used for the preparation of the mixture of inks and for the cleaning of the accessories of the machines of impression.

The chemical products used are: Ethyl acetate, Ethanol, Methoxypropanol, and glue.

With a total of 78 employees (including 30 permanent), the company adopts the 48 hours mode per working week posted $(3 \times 8)$ from 6 to $14 \mathrm{~h}, 14$ to $22 \mathrm{~h}$. and 22 to $06 \mathrm{~h}$.

On sight, there were no canteen facilities. Employees usually take their meals in offices, locker rooms or even in the workshops.

\subsection{Characteristics of the population:}

$\checkmark$ The average age of the sample was $38.8 \pm 2$ years. The majority of them $(58 \%)$ were over 40 years old.

$\checkmark$ The distribution by seniority in the workplace shows an average of seniority of $14 \pm 3$ years. In $41 \%$ of cases, the seniority is over 20 years.

$\checkmark$ The distribution by gender shows that the company recruits male employees. The sex ratio is 6.09 .

$\checkmark$ The ratio of supervision of staff is $50 \%$.

$\checkmark \quad$ The rate of absenteeism due to sick leave and occupational injuries exceeded the target of management $(1.5 \%)$ with a peak $(5 \%)$ in the month of July.

\subsection{Ergonomic analysis of real activity}

Printing is dedicated to the production of flexible packaging for food (biscuit, chocolate, drinks, etc.) based on films polypropylene, polyester, aluminum, paper, etc. The production process is an online process as follow:

\section{a-The working process}

It is provided by three large machines with different specifications and performances.

\section{The first machine:}

"Helio" Unit: This is a chain of printing using varieties of inks: ethyl acetate (50\%) and ethanol $(50 \%)$. Four (4) operators each shift was in charge of this unit. E.g.: 


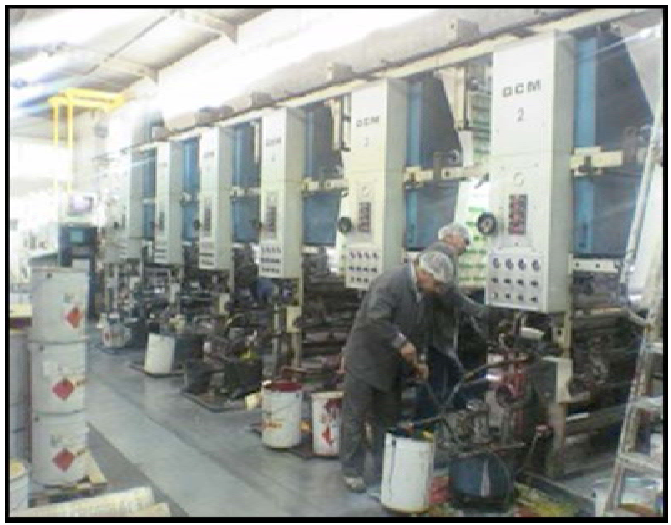

Fig. 1: the "Helio" Unit

The second machine:

"Soloflex" Unit: This printing unit used a printing ink based on ethyl acetate (18\%), ethanol (69\%) and ethoxy propanol (13\%). Two workers per shift are working on the chain. E.g.:

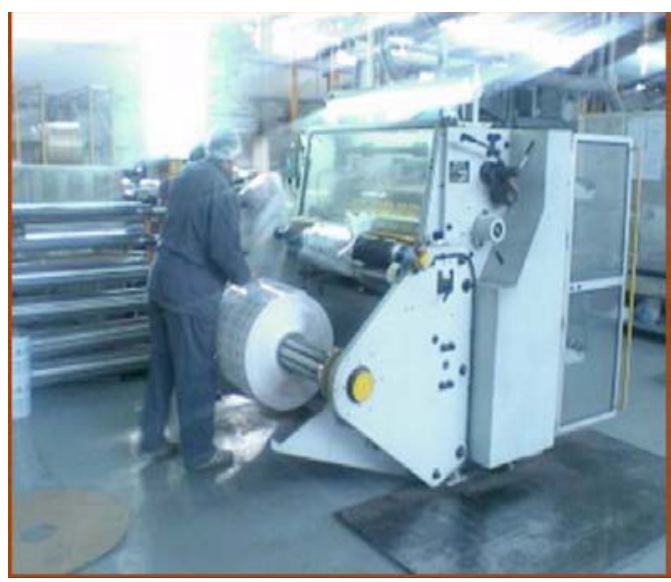

Fig. 2: the "Soloflex" Unit

The third machine:

Simplex Unit (lamination): This unit prints paper collage on a support inside packaging (aluminum foil). This operation uses polyurethane glue. This adhesive is distributed automatically by an electric pump (there is no direct contact with the glue).

For these three units, ventilation is both natural and artificial provided by windows and a door. Two extractors are placed above the three units studied. The exhibition is an ongoing process of 8 hours daily.

The "Helio" machine is the oldest; it lost more of its functions, therefore, less automation and more exposure to solvents. Its operation is almost manual, requiring the constant presence of operators to supply it with ink and control its operation.

\section{b- Ink preparation unit:}

The mixture of ink is preparing in special room with an area of $20 \mathrm{~m}^{2}$. The solvents handled are ethyl acetate, ethanol and methoxy propanol.

In this unit ventilation is ensured by an open door. The operators do not wear their PPE.

\section{c- Cleaning unit:}

This is a room area of $20 \mathrm{~m}^{2}$, located outside the plant. Inside, there is a table, in the back of the room, where the objects are superimposed for washing. The lighting is low, provided by a single lamp, with dark walls and poorly maintained. The ventilation is inadequate, provided by the door and a window to his left, which is often closed in winter and summer. E.g.:

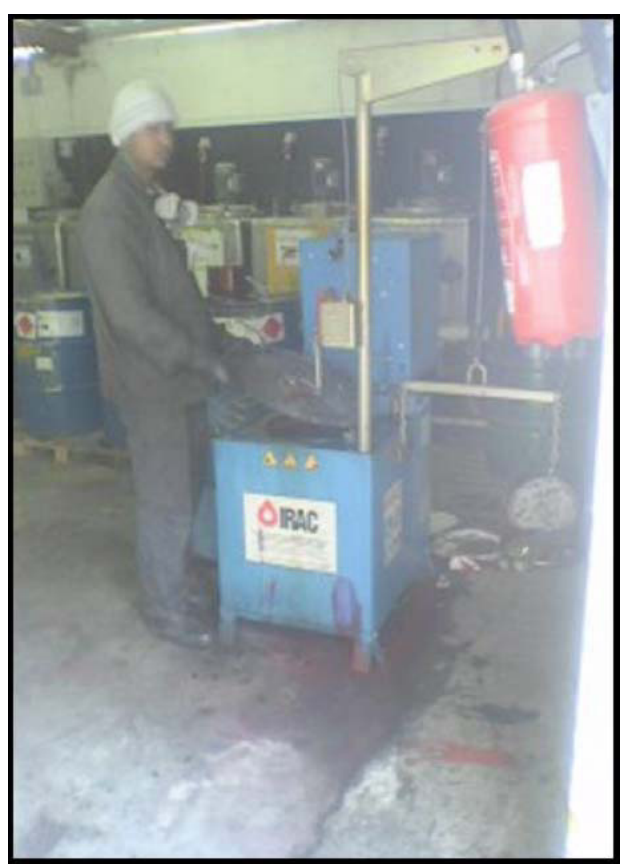

Fig. 3: the cleaning Unit 
A young employee (24 years), new recruit (for 6 months following the occupational reclassification of former operator victim of occupational disease) works in this Unit. Its status is contractual and in trial period. He is working alone, without help or rotation with someone else. The wearing of PPE is virtually absent. In this unit, the exposition is irregular. It is on average 6 hours per day.

The task consist to clean the accessories of printing with the ethyl acetate (scrapers, ink fountains, pipes, plates, ink carts, large trays, inkwells caches and blades) and to recycle ethyl acetate by distillation operation for reuse in cleaning. The reason of the cleaning operation is to have accessories clean and free of traces, that is, to remove the remnants of ink pasted on the metal surface of accessories to ensure a good quality of print in terms of sharpness and color fidelity.

To achieve this, the operator exerts a double control:

- Touch: by passing his hand several times on the surface of the total cleaning up.

- Visual: by the look by sweeping the same area to ensure the fulfillment of the task.

\subsection{Measurement of solvents and noise}

The measurement of solvents gives the following values (see Table 1).

The measured average concentrations are lower than the standards for solvents analyzed (Acetate of ethyl, Ethanol, Methoxypropanol) in all the studied units. The degree of concentration of the mixture is lower than in all the studied units.

For the cleaning unit, the average concentration of the ethyl acetate $(360 \mathrm{ppm})$ is close to the average value of exposure (400 ppm)

The average noise exposure levels (Leq) varies from 85 to $90 \mathrm{~dB}(\mathrm{~A})$ except for the station of aluminum winding where the noise is impulse and recorded Lpeak reached $111 \mathrm{~dB}(\mathrm{~A})$.

\section{Discussion}

This approach seeks to identify situations where workers are simultaneous exposure to noise and mixture of organic solvent (Chang et al. 2009), based on occupational analysis of the activity (Mohammed-Brahim \& Garrigo, 2009). The monitoring of the work environment based on atmospheric measurements of the main pollutant (ethyl acetate) was performed. These atmospheric sampling in workplaces showed:

- very low values in places of ink preparing for "Helio" printer :158.6 ppm,

- Low values in workplaces of Helio unit: 73.7 ppm and "soloflex" unit: $73.7 \mathrm{ppm}$,

- high values at the cleaning workplaces: $369.2 \mathrm{ppm}$,

These values, though, do not exceed the limits "standards: 400 ppm" should arouse our attention. Indeed, the sampling conditions may change from one moment to another [Sliwinska-Kowalska et al, 2005] in relation to climatic conditions (solvent evaporation during the hot season and worsening conditions in the winter by closing the door of the factory that is the only means of ventilation).

Majority of workers are exposed to chemical mixtures. Health criteria generally do not take into account the possibility of interactions. The nature of the possible interactions (Additivity; Supraadditivity (synergy or potentiation); Infra-addivity) will be mentioned.

When two or more hazardous substances are present in the workplace and have similar effects on the same organs of the human body, their effects are considered to be additive, unless established otherwise. Moreover, the average noise exposure levels (Leq) exceed the standards (more than 80 $\mathrm{dB}(\mathrm{A}))$. This is a factor of potentiation.

The working conditions in printing are exacerbated by the scattering of implements, often open without cover throughout the machine, associated with the release of solvent vapors from utensils, and poor ventilation (no vacuum system or extractors or even windows) creates an exposure to solvents in all positions working with different concentrations.

The printer "Helio" is the oldest, worked initially in vacuum, but it lost that status requiring employees to adapt to this new situation. They feed it manually by vessels containing the mixture of ink. This machine needs a constant supply of ink throughout the printing process. This has created new working conditions: utensils are scattered throughout the workplace.

The toxic hazard in this post is not just for the operator's printers. It also applies to operators of other stations laminating and cutting. Indeed, the three printers emit strong odors that are amplified by the odors from feeding buckets and barrels of storage installed on the side of the "helio" printer. 
The ventilation and air conditioning is insufficient, provided only through the front door.

The reflection of sunlight falling on the side of the printer "Helio," creates a glare that forces the operator during visual checks of the film to break into the machine to be able to monitor the coil that makes him inhale a quantity important to the smell of solvent. Finally, the spatial design of the main local exposes all workers (operators, printers), by its present configuration at the same time, to toxic and noise risk. Indeed, the position of lamination and cutting are exposed to the odor of the solvent used by printers, due to their installation in the same space without any separation,

Evaluation of working conditions in these positions showed the absence of direct exposure to solvents. However, indirect exposure to low doses is due to the relative proximity of the print stations and lack of ventilation in the plant.

The cleaning workplace is occupied by a single operator (young, new recruit with a fixed term contract and trial period). Indeed, the worker must give more than him-self without demands or challenges. The room reserved for this task is obscure, low-light and dull walls, ventilation is ensured by the door and a window to his left but generally closed, there is no extractor fan or host. Physical properties of materials, process conditions, equipment types, as well as work activities influence exposure to chemicals through inhalation [Hassim \& Hurme, 2010]. As for skin contact and ingestion, poor hygiene practices and work procedures appear to be the notable cause. Compounding more solvent exposure is the fact that the task of cleaning is done at the back of the room in a darker and less airy. And since cleaning is to "wash" in ethyl acetate all items of work (squeegees, ink, plates, etc.) to make them fit for further use, the operator must clean up to remove any the residual ink.

The quality criteria are provided by a double check: touch and visual scan. To succeed in his task, despite the disadvantaged working conditions, the employee is obliged to approach to visually check the room. Thus, exposure to acetate is increased further.

The lack of lighting and ventilation associated with poor spatial configuration (the basin of the solvent is installed at the back of the room) requires the operator:

- First, approach nearest the container in order to perform visual inspection
- Second, remove the mask to clear the view on one hand and avoid the sensation of heat on the other.

Thus, the physical and spatial factors contribute to increase the risk of toxicity. The non-wearing of PPE by this operator can be explained by the fact of the absence of the ability to "do otherwise". Indeed, the operator adopts a compromise to achieve the objectives of production to the detriment of his health and his safety.

In interviews conducted with operators, a general state of psychosis was felt among the workers, pointing to the cleaning workplace as dangerous and threatening their health and their lives. This state of mind was triggered as a result of a reclassification of their colleague who had an occupational disease. This situation has created a climate of panic and anxiety especially for older operators who have more than 20 years exposed to handling toxic products and more exposure to high noise level.

\section{Conclusion}

In the printing industry, workers are exposed to several risk factors, mainly the chemical risk due to handling tasks of various products (inks, solvents, adhesives, etc.) and noise pollution caused by the printing process.

The ergonomic evaluation of co-exposure to solvents and noise in the printing company of the present study showed many drawbacks, which can be overcomed through the following recommendations:

- Increasing natural ventilation and improving the system of general ventilation by installing a vacuum system at the source of solvent vapors in the cleaning unit.

- Providing adequate covers for the various tanks containing solvent mixtures with other substances, and installing efficient air conditioning.

- Selecting PPE including gloves and gas masks by specialists (occupational physician, hygienist, ergonomist), and involving workers in the choice of PPE (masks, goggles, overalls, gloves,).

- Making sure of the real port of PPE (masks with cartridges specific gaseous pollutants, ear plugs, ear impressions or earmuffs).

- Monitoring regularly the atmospheric concentration of the handled solvents. 
- Implementing the general rules of hygiene, especially the prohibition of eating, drinking or smoking in the workplace

- Maintenance of machinery (replacement of worn parts, lubrication, maintenance and/or replacement of bearings, etc.) and isolation of areas with high intensities by shields (material absorbing sound energy).

\section{References}

[1] Chang, TY., Wang, VS., Hwang, BF.,Yen; HY., Lai; JS., Liu; CS., Lin; SY.; 2009. Effects of co-exposure to noise and mixture of organic solvents on blood pressure. J Occup Health.51(4):332-9.

[2] Garcia, A.M., 2003. Pesticide exposure and women's heath. American Journal of Industrial Medicine, 44 66, pp. 548594.

[3] Garrigou, A., Baldi, I., Le Frious, P., Anselm, R., Vallier, M., 2011. Ergonomics contribution to chemical risks prevention: An ergotoxicological investigation of the effectiveness of coverall against plant pest risk in viticulture. Applied Ergonomics 42, 321-330.
[4] Garrigou, A., Vallier, M., Pasquereau, P., Carballeda, G., Faure, A., Ferenc, T., Carayon, B., 2009. An ergotoxicological approach of the shipbuilding workers exposition to solvents. In: Abstracts of the XVIIth IEATriennial Congress, August 9-14, 2009, Beijing.

[5]Hassim, M.H., Hurme, M., 2010. Inherent occupational health assessment during process research and development stage. Journal of Loss Prevention in the Process Industries 23, 127138

[6] Mohammed-Brahim, B., Garrigou, A., 2009. Une approche critique du modèle dominant de prévention du risque chimique. L'apport de l'ergotoxicologie. @ctivités 6 (1), 4967. http://www.activites.org/v6n1/brahim.pdf.

[7] Sliwinska-Kowalska M., Zamyslowska-Szmytke E., Wieslaw Szymczak, W., Kotylo, P., Fiszer, M., Wesolowski, W., Pawlaczyk-Luszczynska M., 2005. Exacerbation of noiseinduced hearing loss by co-exposure to workplace chemicals. Environmental Toxicology and Pharmacology 19, 547-553. 
Table 1: distribution of solvent concentration and noise level by workplace

\begin{tabular}{|l|l|l|l|l|l|}
\hline Workplaces & Ethyl acetate & Ethanol & Methoxy propanol & ${ }^{*} \mathrm{R}_{\mathrm{m}}$ & ${ }^{* *} \mathrm{~L}_{\mathrm{eq}}$ \\
\hline Helio Unit & 102,3 & 36,6 & - & 0,28 & 89 \\
\hline Soloflex Unit & 73,7 & 83,5 & 5,7 & 0,32 & 89 \\
\hline Unité Simplex & 52,9 & - & 6,7 & 0,20 & 87 \\
\hline Ink preparation unit for Helio & 158,6 & - & - & 0,39 & 80 \\
\hline Ink preparation unit for Soloflex & 133,8 & 12.6 & - & 0,34 & 81 \\
\hline Cleaning Unit & 359,9 & - & - & 0,9 & 85 \\
\hline
\end{tabular}

* Rm : mixture exposure index

** Leq: noise Level equivalent 